\title{
A brief analysis of challenges in implementing telehealth in a rural setting
}

\author{
Varadraj P. Gurupur ${ }^{1}$, Zhuqi Miao ${ }^{2}$ \\ ${ }^{1}$ School of Global Health Management and Informatics, University of Central Florida, Orange County, FL, USA; ${ }^{2}$ Center for Health Sciences, \\ Oklahoma State University, Stillwater, Payne County, OK, USA \\ Contributions: (I) Conception and design: VP Gurupur; (II) Administrative support: VP Gurupur; (III) Provision of study materials or patients: None; \\ (IV) Collection and assembly of data: None; (V) Data analysis and interpretation: None; (VI) Manuscript writing: Both authors; (VII) Final approval \\ of manuscript: Both authors. \\ Correspondence to: Varadraj P. Gurupur. 528 W. Livingston Street, Suite 401, Orlando, FL 32801, USA. Email: varadraj.gurupur@ucf.edu.
}

\begin{abstract}
Available literature clearly indicates that successful implementation of telemedicine and telehealth has been a challenge. This challenge is further amplified if the reader must consider this implementation in a rural setting. In this article the authors discuss some of the key challenges associated with this implementation. The article sheds light on a few key studies and commentaries associated with the use of telehealth in a rural setting. Critically, the article summarizes these critical findings; thereby, informing the reader on the bottlenecks associated with the use of telehealth in a geographically rural area. Also, briefly summarizing the existing body of knowledge on this topic of study. Furthermore, a case study briefly narrating the use of telemedicine and telehealth for rural Oklahoma is presented to advance our understanding of the situation in this field. Some of the critical details associated with this case study provides insights on some of the key challenges associated with the implementation of telehealth in a rural setting. This case study also provides insights on key workflow processes that helped the implementation of telehealth. Finally, the authors summarize the key challenges in the implementation of telehealth based on their perspective. Here it is important to inform the readers that this article is not a scientific review on the topic instead presents an opinion backed by facts and existing literature. Overall, the authors present a key discussion that can lead to advances in research and required innovations that might help in providing easy access to healthcare through telehealth.
\end{abstract}

Keywords: Rural health; telehealth; telemedicine; healthcare service; issues with telehealth implementation

Received: 10 September 2021; Accepted: 16 December 2021; Published: 20 April 2022.

doi: $10.21037 /$ mhealth-21-38

View this article at: https://dx.doi.org/10.21037/mhealth-21-38

\section{Basic concepts and definitions}

Grigsby and Goetz (1) define telehealth as, "the use of telecommunications and computer technologies to make a broad spectrum of health-related services and information available to populations with limited access". Moreover, Institute of Medicine defined telemedicine in 1996 as (2), "the use of electronic information and communications technologies to provide and support health care when distance separates participants". In this work the authors consider telemedicine as a part of telehealth and discuss the issues related to the implementation of telehealth in a rural setting. Generally, telemedicine is a subset of telehealth. Grigsby and Goetz (1) indicate that telehealth may include several categories of care such as: teleradiology, mental health, ER/triage, and chronic disease management. Here it can be conceived that telemedicine is a subset of telehealth.

Now that we have explored the definitions of telemedicine and telehealth it is important to investigate into what constitutes as a rural area in the United States. It is important to mention that the US Census Bureau defines rural as something that is not urban. In other words, any 
geographical area that is not covered under the definition of urban is rural. This leads the reader into investigating the definition of an urban area. The US Census Bureau defines an urban area as a geographical location that has a nucleus of 50,000 or more people. Additionally, it is important to note that the US Census Bureau document for the year 2020 states that, "the Census Bureau would identify urban areas of 4,000 or more housing units or 10,000 or more persons without distinguishing types of urban areas" (3). Thereby, we have now covered the definitions for telehealth and rural area in the United States. It is also important to mention that Rural Urban Commuting Area (RUCA) designation is provided by the United States Department of Agriculture. A recent study conducted by Plante et al. (4) indicated that there is some difficulty with concordance of rural area identification by individuals to that indicated by the RUCA code. This means that before we dive into the challenges of implementing telehealth in rural areas it must be noted that there are challenges in the very identification of a rural area as far as United States is concerned.

\section{Discussion on challenges with implementation of telehealth in rural areas}

Based on the available literature the implementation of telehealth in an urban setting is easier than rural parts of United States. This also indicates that the key challenges in the implementation of telehealth are in the following broad areas: (I) availability of wireless/wired networks; (II) efficacy of the rural population in using telemedicine; and (III) more importantly profitability of telemedicine implementation setup. Nelson (5) clearly delineates that urban hospitals provide more telehealth services than rural hospitals. If this is the case, it is important to investigate into the reasons for this dichotomy. From this perspective, Gurupur et al. (6) have illustrated that ethnicity, age, education, and household income were critical factors in the acceptability of telemedicine use in rural parts of northern Louisiana. In this age, education, and household income were more significant than ethnicity. Among this education was the most significant factor. Many times, clinicians attempt to improve the knowledge acquired on a particular disease or disorder to improve telemedicine usage. Here the term education implies education acquired by patients and/or caregivers on a particular disease or disorder. In this context West et al. (7) used telemedicine and diabetes education to achieve change in the behavior of patients in rural settings.

In addition to these factors that pertain to the use of telemedicine usage from a patient's perspective it is also important to note that there exist challenges from a provider's perspective. A critical hurdle here would be challenges associated with legal, ethical, and best practice guidelines (8). The legal issues would mainly encompass the implementation of Health Insurance Portability and Accountability Act (HIPAA). The hardware and the associated communicating devices must be HIPAA compliant and protect the privacy, and integrity of electronic health records. Incidentally, according to Dart et al., (8) this situation also presents a barrier from an ethical perspective. For example, access to health information may be available without informed consent. Interestingly Fields (9) argues that there could be other barriers from an ethical point of view; one of them being conflict of interest. Here the author points at the following legal regulatory considerations: (I) informed consent; (II) licensing; (III) clinical privileges and credentials; (IV) Internet prescribing; (V) conflicts of interest; (VI) malpractice insurance; and (VII) protected health information. A key comment on ethical use here is that it is not the hardware and software that is used in telemedicine that creates the problem, but it is the method of use that needs to be carefully considered. A rural setting where patients lack an appropriate level of education might be a fertile environment for violation of one or more of these regulatory standards. In addition to this a lower income level for the patient may also mean reduced accessibility to legal advice. This in turn can potentially lead to some form of stigma or lack of efficacy towards the use of telehealth.

Batsis et al. (10) identify five main challenges in implementing telehealth in rural areas: (I) the organization's willingness to implement telehealth to improve access to its patients; (II) availability of the necessary infrastructure for implementing telehealth; (III) implementation of models for reimbursements for telehealth use; (IV) availability of required training, knowledge, and education for providers; and $(\mathrm{V})$ implementation of quality assurance models to implement continuous and feedback process. Here it is important to mention that reliability of broadband networks in rural areas is as important as its availability. Here it is important to go back to the concept of efficacy of use in terms of telehealth for patients living in that area. The clinics and hospitals will be more inclined towards investing in infrastructure for telehealth if potential patients in that geographical region have a higher efficacy 
that crosses the threshold. Here the threshold is best decided by the healthcare vendors. In a situation where the organization is fully prepared to implement telehealth the lack of availability of infrastructure may lead to its non-implementation. Even if both these conditions are satisfied the lack of efficient models for re-imbursement of telehealth services may jeopardize its implementation and if implemented may also lead to financial troubles for the healthcare vendor. Also, from a financial and a usability perspective it is important to collect feedback and improve the processes involved in telehealth.

Raffenaud et al. (11) used the Theory of Planned Behavior to measure the usability of telemedicine use for a study sample from a rural setting. This study indicated that the following factors improved the favorability of telemedicine use: (I) perceived benefits: savings in travel cost to the healthcare provider, and reduced wait times at the healthcare facility; (II) perceived motivation: improved clinical feedback from the clinicians, and quicker response time; (III) perceived compatibility and advantage: increased accessibility to healthcare service, and clinicians. The same study also indicated that there was an increase in favorability with increase in education and with lower age. The key negative factors negatively impacting favorability of telemedicine use included: (I) perceived anxiety; and (II) perceived complexity. This was a clear indication that the negative perception was present in the idea of telehealth being a complex technically advanced less understood process. This probably indicates that familiarity with telehealth can mitigate these problems dealing with favorability.

Batsis et al. (10) also indicate that one of the most important specialty in terms of challenge in implementation would be geriatrics. This is also corroborated by Gurupur et al. (6), where the authors clearly indicate that age could be one of the factors that has negative correlation with the likeability of telemedicine use. However, from a slightly different perspective, Brignell et al. (12) argue that telemedicine will improve the accessibility of healthcare to older adults. Stowe and Harding (13) mention the term "gerotechnology" and present the aspect of telehealth being a part of this concept. Overall, from a geriatric point of view telehealth may be a bitter medicine for most of the older adults in rural areas with a mitigation in this bitterness with the increase in level of education.

Although Cusack et al. (14) indicate that about $\$ 4.3$ billion per year could be saved using hybrid telehealth services the challenges involved in implementing telehealth may create an unfathomable stumbling block in its implementation in the rural areas. From a healthcare provider's perspective, the most important factor would be the reimbursement for telehealth services. Although this problem may have considerably diminished in the post COVID-19 pandemic era. The acceptability of telemedicine and the greater problem of digital divide may impede patients from accessing telehealth services. Interestingly, Martin et al. (15) indicate that rural hospitals in United States are more ready for the use of telemedicine and telehealth through readiness and required education.

\section{Case study}

In spite of many solutions focused on increasing headcount of doctors and simplifying licensure requirements in the US, the gap between the supply and demand of physicians continues growing due to the inherently slow and costly nature of the growth of healthcare workforce. According to Association of American Medical Colleges, the shortage of physicians is projected to grow to between 61,800 and 131,000 by 2030 , which is $7 \%$ to $16 \%$ of the entire physician workforce (16). The situation is particularly dire in rural areas, where resides over sixty million Americans. Compared to their urban counterparts, rural Americans are poorer, older, and sicker. Additionally, they suffer from a stretched and diminishing rural health workforce and insurance affordability issues, which even exacerbate their access to specialty and primary care providers. For example, Oklahoma is a state where nearly one-third of its population is rural, and thirty-nine tribes call Oklahoma home. Not only does Oklahoma consistently rank among the worst in health outcomes, but in terms of access to care, Oklahoma is ranked 48th for the number of primary care physicians per capita (17). To "Transform Rural and Native American Health" in Oklahoma, the Center for Health Systems Innovation (CHSI) at Oklahoma State University established the Institute for Predictive Medicine (IPM) to find innovative solutions based on telehealth and big data to improve the health access in rural Oklahoma.

A remarkable telehealth technology CHSI-IPM has developed is the early detection tool for diabetic retinopathy (DR) $(18,19)$. DR is a leading cause of blindness among working-aged adults globally. Since DR can progress to irreversible stages (vision is unable to be restored) asymptomatically, early detection and 
Table 1 The DR risk scoring system developed in CHSI-IPM, adapted from (19)

\begin{tabular}{|c|c|c|}
\hline Variables & Levels & Scores \\
\hline \multirow[t]{6}{*}{ Age (years) } & $18-34$ & 12 \\
\hline & $35-49$ & 9 \\
\hline & $50-64$ & 6 \\
\hline & $65-74$ & 4 \\
\hline & $75-84$ & 2 \\
\hline & $\geq 85$ & 0 \\
\hline \multirow[t]{5}{*}{ Creatinine } & $<0.5$ & 0 \\
\hline & $0.5-1$ & 3 \\
\hline & $1-1.5$ & 8 \\
\hline & $1.5-2$ & 12 \\
\hline & $>2$ & 21 \\
\hline \multirow[t]{5}{*}{$\mathrm{HbA} 1 \mathrm{c}$} & $<6$ & 0 \\
\hline & $6-8$ & 6 \\
\hline & $8-10$ & 12 \\
\hline & $10-12$ & 18 \\
\hline & $>12$ & 28 \\
\hline \multirow[t]{2}{*}{ Neuropathy } & Negative & 0 \\
\hline & Positive & 10 \\
\hline \multirow[t]{3}{*}{ Sodium } & $<136$ & 0 \\
\hline & $136-144$ & 7 \\
\hline & $>144$ & 13 \\
\hline \multirow{5}{*}{$\begin{array}{l}\text { Diabetic duration } \\
\text { (years) }\end{array}$} & $<1$ & 0 \\
\hline & $1-2$ & 2 \\
\hline & $2-3$ & 3 \\
\hline & $3-4$ & 5 \\
\hline & $>4$ & 14 \\
\hline \multirow[t]{5}{*}{ WBC } & $<4$ & 17 \\
\hline & $4-6$ & 15 \\
\hline & $6-8$ & 13 \\
\hline & $8-12$ & 9 \\
\hline & $>12$ & 0 \\
\hline \multirow[t]{2}{*}{ Nephropathy } & Negative & 0 \\
\hline & Positive & 6 \\
\hline
\end{tabular}

Table 1 (continued)
Table 1 (continued)

\begin{tabular}{lcc}
\hline Variables & Levels & Scores \\
\hline Glucose & $<60$ & 0 \\
$60-80$ & 1 \\
$80-100$ & 2 \\
$100-200$ & 6 \\
Hematocrit & $<200$ & 20 \\
& $<30$ & 19 \\
$30-35$ & 15 \\
$35-40$ & 11 \\
$40-50$ & 7 \\
$>50$ & 0 \\
\hline
\end{tabular}

DR, diabetic retinopathy; CHSI-IPM, Center for Health Systems Innovation-Institute for Predictive Medicine; WBC, white blood count.

treatment are crucial to prevent DR and the subsequent vision loss (20). However, early screening of DR suffers from the poor compliance with annual ophthalmological examinations and lack of specialists/equipment to deploy comprehensive screening programs, especially in rural/ undeveloped areas (21). Current telemedicine solutions for DR detection are mainly revolving around analyzing retinal images $(22,23)$. However, given the poor compliance with ophthalmological examinations in rural communities, the effectiveness of traditional telemedicine in DR early detection is questionable. By contrast, the DR predictive technology developed in CHSI-IPM only requires a few common patients' biomarkers, mainly routine lab results, thus significantly easier and cheaper to be adopted by rural patients and doctors. The development of the techniques was based on a large diabetic cohort extracted from Cerner Health Facts EHR database. The cohort included 3,749 DR patients and 94,127 non-DR diabetic patients. The large volume of data allowed feature selection to find ten essential DR predictors among twenty-six variables in demographics, duration of diabetes, complications and laboratory results. Based on the selected, essential predictors, a machine learning (ML) model was created to predict the DR incidence in six months for diabetic patients with a high accuracy (0.85 AUC). The essential predictors further enabled the development of an interpretable risk scoring system, as shown in Table 1. The risk score not only achieve 


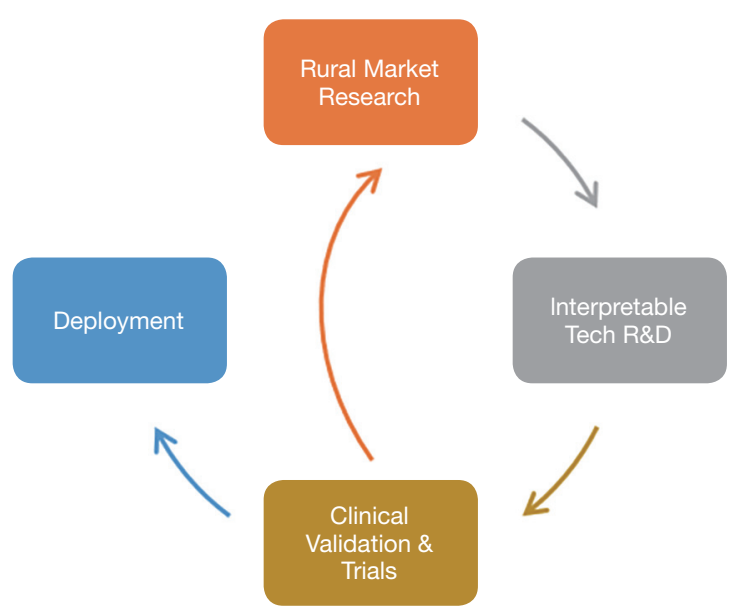

Figure 1 Workflow for the development and implementation of telehealth in rural settings.

a good prediction accuracy (0.77 AUC) comparable with ML, but also provide a "white box" for doctors, nurses and patients to understand and explain the risk. The developed ML model and risk score were then tested in the University of Kansas Medical Center (KUMC). The test included EHR data from a study cohort consisting of 869 DR and 6,448 non-DR diabetic patients. The testing accuracies of the ML model and risk score were 0.81 and 0.73 respectively, which were very close to their performances on Cerner data. Therefore, the generalizability of the DR early detection techniques was validated.

Furthermore, CHSI-IPM is improving the technology through rural market research. After reaching out to 20 rural clinics/hospitals with questionnaire and interview requests, the team received valid responses from 2 diabetic patients and 4 doctors. Though hardly able to quantify the demand (due to the small sample size and hard-to-estimate nature of the demand), the survey still reveals interesting potentials of the DR early detection technology in the market:

* There are patients who are not aware of DR at all (1 patient's and 1 doctor's responses supported this perspective). Furthermore, many rural patients, even though aware of DR, still are not willing to undergo proper examinations/treatments on time for many reasons, e.g., scared, travelling, costs, poor education, and lack of resources (all doctors' responses supported this point, e.g., "only $20 \%$ would follow through with an eye exam", "the biggest miss-conception people make is that vision is all about glasses", and "Most hospitals in suburban areas do not have the necessary machines").

* Four responses (1 patient's and 3 doctors') explicitly stated that the technology is a helpful tool for DR prevention. It can contribute to the healthcare cost reduction, and such tools are uncommon in market. Supportive comments include "predictive technology would motivate patients enough to visit an ophthalmologist", "prevention is always, always, always cheaper", and "as per my knowledge there is no such tool in the market".

* Suggested improvements included better prediction accuracy, more user-friendly interface, and coverage by insurance, etc.

Based on the market feedback, the improvements are focused on (I) introducing more advanced models/ algorithms to enhance the DR prediction accuracy; and (II) integrating all the predictive techniques into a user-friendly computer/mobile app. The improvement effort recently awarded a \$1.2 million NIH R01 grant, which will support related investigations for four years (24). In long-term, this study will provide efficient and cost-effective tools that allow rural patients and physicians to detect DR risk at an early stage and take prompt actions to reduce the DR incidence in rural communities.

This case study demonstrated an effective workflow (as shown in Figure 1) to succeed in developing and implementing telehealth in rural settings. In addition to the R\&D of technology and the clinical validation/trials, business insights in rural healthcare settings gained through market research and customer discovery is also essential for a successful telehealth implementation. These three elements form the key steps of the workflow.

\section{Summarizing the discussion}

Overall, in this article the authors have attempted to perceive the challenges associated with the use of telehealth in a rural setting. Here it is important to summarize the key points elaborated by the author as illustrated in Table 2. The author perceives that it is important to identify these challenges and bottle necks to successfully implement telehealth in a rural setting. Implementation of telehealth in a rural setting has the power to bring about a paradigm shift in healthcare delivery making healthcare accessible to a large population. This is not only true in the United States but also for those countries with large rural populations. 
Table 2 Key challenges to adoption of telehealth in rural areas

\begin{tabular}{|c|c|}
\hline Challenge & Brief description \\
\hline Anxiety & Individuals who do not have enough experience dealing with technology may get anxious \\
\hline Specialty & $\begin{array}{l}\text { A few specialties such as geriatrics may be difficult to implement using telehealth due to older adults not } \\
\text { being accustomed to newly available technology }\end{array}$ \\
\hline Reimbursement of services & $\begin{array}{l}\text { There is a possibility that healthcare providers may not get re-imbursed for some types of services } \\
\text { provided through telehealth }\end{array}$ \\
\hline Constant improvement & Constant improvement of telehealth services needs service hours, dedication, and motivation \\
\hline
\end{tabular}

\section{Acknowledgments}

The authors would like to thank the Guest Editors Dr. Donna Slovensky and Dr. Donna Malvey for providing the opportunity to contribute to the special series.

Funding: None.

\section{Footnote}

Provenance and Peer Review: This article was commissioned by the Guest Editors (Donna J. Slovensky and Donna M. Malvey) for the series "mHealth: Innovations on the Periphery" published in mHealth. The article has undergone external peer review.

Conflicts of Interest: Both authors have completed the ICMJE uniform disclosure form (available at https://mhealth. amegroups.com/article/view/10.21037/mhealth-21-38/ coif). The series "mHealth: Innovations on the Periphery" was commissioned by the editorial office without any funding or sponsorship. The authors have no other conflicts of interest to declare.

Ethical Statement: The authors are accountable for all aspects of the work in ensuring that questions related to the accuracy or integrity of any part of the work are appropriately investigated and resolved.

Open Access Statement: This is an Open Access article distributed in accordance with the Creative Commons Attribution-NonCommercial-NoDerivs 4.0 International License (CC BY-NC-ND 4.0), which permits the non- commercial replication and distribution of the article with the strict proviso that no changes or edits are made and the original work is properly cited (including links to both the formal publication through the relevant DOI and the license). See: https://creativecommons.org/licenses/by-nc-nd/4.0/.

\section{References}

1. Grigsby W, Goetz SJ. Telehealth: What promise does it hold for rural areas? In: Glasgow N, Morton LW, Johnson NE. editors. Critical Issues in Rural Health. WileyBlackwell; 2004.

2. Lustig TA. The role of telehealth in an evolving healthcare environment, The National Academies Press, Washington D.C.; 2012.

3. Mussatt D. Urban Areas for the 2020 Census-Proposed Criteria. Federal Register 2021;86:10237-43.

4. Plante TB, Koh I, Wilcock AD. Concordance of Rural Identity and ZIP Code-Linked Rural-Urban Commuting Area (RUCA) Code. J Rural Health 2020;36:143-4.

5. Nelson R. Telemedicine and Telehealth: The Potential to Improve Rural Access to Care. Am J Nurs 2017;117:17-8.

6. Gurupur V, Shettian K, Xu P, et al. Identifying the readiness of patients in implementing telemedicine in northern Louisiana for an oncology practice. Health Informatics J 2017;23:181-96.

7. West SP, Lagua C, Trief PM, et al. Goal setting using telemedicine in rural underserved older adults with diabetes: experiences from the informatics for diabetes education and telemedicine project. Telemed J E Health 2010;16:405-16.

8. Dart EH, Whipple HM, Pasqua JL, et al. Legal, 
Regulatory, and Ethical Issues in Telehealth Technology,

Computer-Assisted and Web-Based Innovations in Psychology, Special Education, and Health, Elsevier Academic Press; 2016:339-63.

9. Fields BG. Regulatory, Legal, and Ethical Considerations of Telemedicine. Sleep Med Clin 2020;15:409-16.

10. Batsis JA, Pletcher SN, Stahl JE. Telemedicine and primary care obesity management in rural areas - innovative approach for older adults? BMC Geriatr 2017;17:6.

11. Raffenaud A, Gurupur V, Fernandes SL, et al. Utilizing telemedicine in oncology settings: Patient favourability rates and perceptions of use analysis using Chi-Square and neural networks. Technol Health Care 2019;27:115-27.

12. Brignell M, Wootton R, Gray L. The application of telemedicine to geriatric medicine. Age Ageing 2007;36:369-74.

13. Stowe S, Harding S. Technology applied to geriatric medicine: Telecare, telehealth and telemedicine. European Geriatric Medicine 2010;1:193-7.

14. Cusack CM, Pan E, Hook JM, et al. The value proposition in the widespread use of telehealth. J Telemed Telecare 2008;14:167-8.

15. Martin AB, Probst JC, Shah K, et al. Differences in readiness between rural hospitals and primary care providers for telemedicine adoption and implementation: findings from a statewide telemedicine survey. J Rural Health 2012;28:8-15.

16. Association of American Medical Colleges, The Complexities of Physician Supply and Demand: Projections From 2018 to 2033, 2018. Available online: https://www.aamc.org/system/files/2020-06/stratcommaamc-physician-workforce-projections-june-2020.pdf

\section{doi: $10.21037 /$ mhealth-21-38}

Cite this article as: Gurupur VP, Miao Z. A brief analysis of challenges in implementing telehealth in a rural setting. mHealth 2022;8:17.
17. Association of American Medical Colleges, 2019 State Physician Workforce Data Report. Available online: https://store.aamc.org/downloadable/download/sample/ sample_id/305/

18. Piri S, Delen D, Liu T, et al. A data analytics approach to building a clinical decision support system for diabetic retinopathy: Developing and deploying a model ensemble. Decision Support Systems 2017; 101:12-27.

19. Wang R, Miao Z, Liu T, et al. Derivation and Validation of Essential Predictors and Risk Index for Early Detection of Diabetic Retinopathy Using Electronic Health Records. J Clin Med 2021;10:1473.

20. Solomon SD, Chew E, Duh EJ, et al. Diabetic Retinopathy: A Position Statement by the American Diabetes Association. Diabetes Care 2017;40:412-8.

21. Ting DS, Cheung GC, Wong TY. Diabetic retinopathy: global prevalence, major risk factors, screening practices and public health challenges: a review. Clin Exp Ophthalmol 2016;44:260-77.

22. Mansberger SL, Sheppler C, Barker G, et al. Longterm Comparative Effectiveness of Telemedicine in Providing Diabetic Retinopathy Screening Examinations: A Randomized Clinical Trial. JAMA Ophthalmol 2015;133:518-25.

23. Shi L, Wu H, Dong J, et al. Telemedicine for detecting diabetic retinopathy: a systematic review and metaanalysis. Br J Ophthalmol 2015;99:823-31.

24. Stacy B. Building the healthcare of the future. Oklahoma State University News and Media - Headlines, 29 October 2021. Available online: https://news.okstate.edu/articles/ business/2021/future_healthcare.html 